\title{
Lower limb weakness with gyrus rectus hematoma: an unusual presentation of paraclinoid aneurysm; a case report with review of literature
}

\author{
Amey P. Patankar ${ }^{1 *}$ (D) and Maulik Vaja²
}

\begin{abstract}
Lower limb weakness is usually a feature of ruptured anterior communicating (ACom) aneurysms due to spasm of the anterior cerebral arteries. Paraclinoid aneurysms, in addition to other cardinal features of subarachnoid haemorrhage (SAH), usually present with headache and visual field defects due to compression of the optic pathway. We report a case of left paraclinoid aneurysm presenting with right lower limb weakness and gyrus rectus hematoma without SAH. The aneurysm was long, passing beneath the optic nerve to emerge in the inter-optic cistern, leading to such atypical presentation. The aneurysm was clipped successfully after drilling the clinoid. As per our knowledge, such a clinical presentation of paraclinoid aneurysm has not been reported in the literature till date.
\end{abstract}

Keywords: Aneurysm, Subarachnoid haemorrhage, Gyrus rectus hematoma

\section{Background}

Weakness of one or both lower limbs due to spasm of anterior cerebral arteries and gyrus rectus hematoma is usually one of the presenting features of ruptured anterior communicating artery (ACom) aneurysms.

Paraclinoid aneurysms give rise to visual field defects due to compression of the optic pathway, in addition to other characteristic signs and symptoms of subarachnoid haemorrhage (SAH).

We report a case of ruptured left paraclinoid aneurysm presenting with lower limb weakness and gyrus rectus hematoma, without cisternal SAH.

\section{Case presentation}

A 40-year-old female presented with right lower limb weakness, headache and vomiting since 5 days. On examination, the Glasgow coma scale (GCS) of the patient was15/15 and pupils were bilaterally equal and reacting to light. Power in right lower limb was $2 / 5$, with

\footnotetext{
* Correspondence: docapp@icloud.com

${ }^{1}$ Department of Neurosurgery, Baroda Medical College and SSG Hospital, 703, Rajarshi Darshan Tower, Near Jalaram Mandir, Karelibag, Vadodara, Gujarat 390018, India

Full list of author information is available at the end of the article
}

normal power in other limbs. Computerised tomography (CT) scan showed hematoma in the left gyrus rectus without cisternal subarachnoid haemorrhage (Fig. 1). Three-dimensional (3D) CT angio of brain showed medially projecting aneurysm arising from the ophthalmic segment of the internal carotid artery (ICA) (Figs. 2 and 3), the suprasellar variant of superior hypophyseal artery aneurysm [1].

Patient presented to us on the fifth day of ictus with neurodeficit due to vasospasm. Hence, patient was treated medically for five more days with tablet nimodipine, phenytoin sodium, analgesics and strict bed rest [2]. Patient's power gradually improved to normal after 3 days. Patient was operated on the 11th day of ictus.

\section{Operative technique}

The patient was operated in supine position with the head fixed in a Sugita clamp. The left side of the neck was kept exposed for gaining control of the ICA in the neck. A standard left pterional craniotomy was done. The frontal sinus which was opened during the craniotomy was exteriorised. The Sylvian fissure was opened widely to release cerebrospinal fluid (CSF) and relax the brain. The carotid artery and optic nerve were identified. 


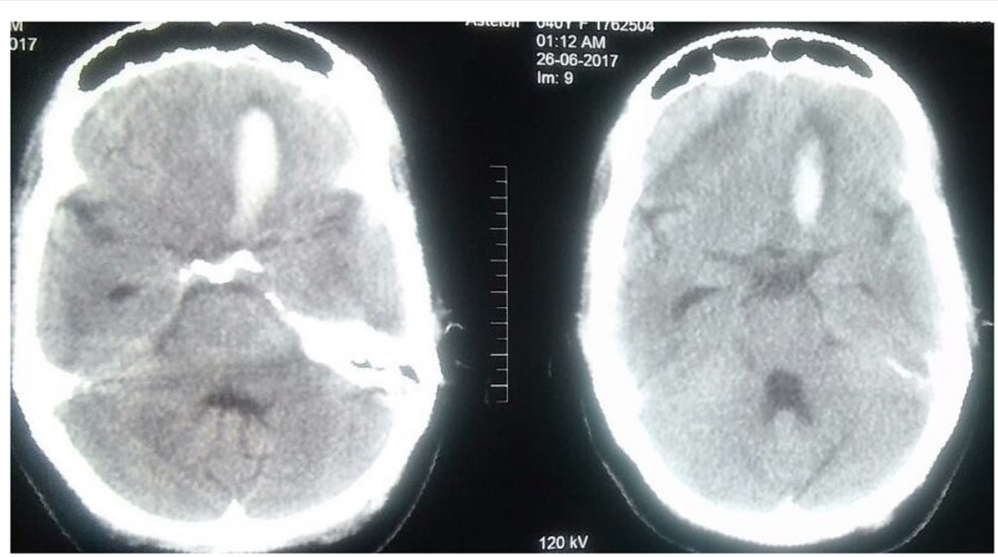

Fig. 1 CT scan of the patient showing hematoma in the left gyrus rectus

The dome of the aneurysm was visible in the inter-optic space adherent to the undersurface to the left frontal lobe.

Next, preparation was made to drill the roof of the optic canal and the anterior clinoid process. The ICA was exposed in the neck to gain proximal control before commencing the drilling. Cuts were made dura over the optic canal and the clinoid process along the lesser wing of sphenoid with no 11 knife [3]. The flap of dura was raised and reflected over the dome of the aneurysm to protect it from rupture during the drilling process. One millimeter diamond burr was used to unroof the optic canal and drill the anterior clinoid process. The falciform ligament over the optic nerve was cut. The distal dural ring was identified and cut. The ophthalmic artery was visualised. The neck of the aneurysm was visible on

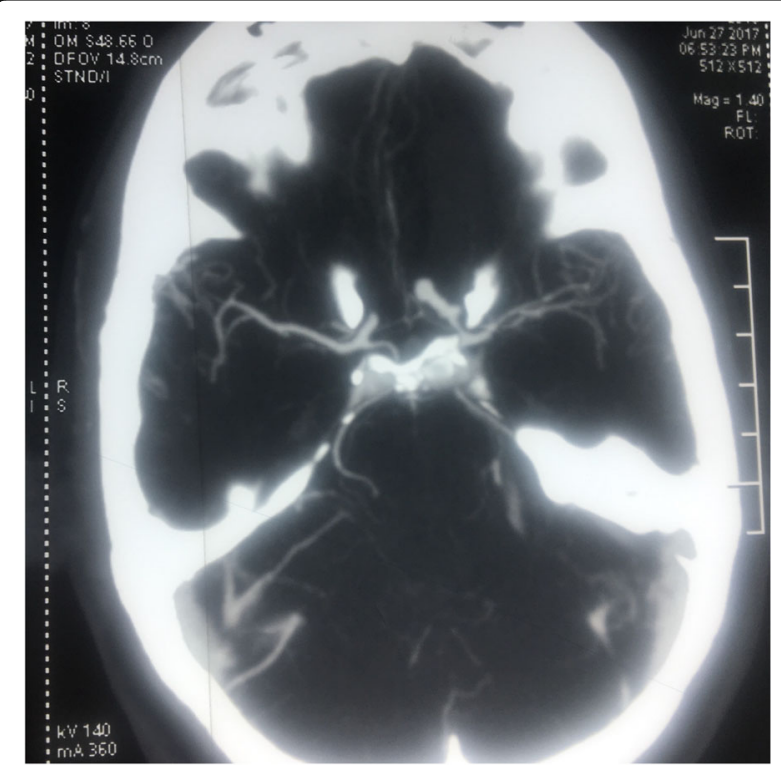

Fig. 2 CT angiography anteroposterior view showing superior hypophyseal artery aneurysm projecting medial to the anterior clinoid process the medial side of ophthalmic artery. The neck of the aneurysm was dissected and space created for the clip blades. Titanium straight clip $10 \mathrm{~mm}$ was passed to secure the neck of the aneurysm.

The dome was then dissected off the frontal lobe and the aneurysm opened. There was no bleeding of the aneurysm. The lamina terminals were opened in the end to drain CSF. The anterior clinoid was packed with muscle and fascia to prevent CSF leak.

Dura and scalp were closed in a standard fashion, with drain in the subgaleal space.

\section{Post-operative course}

The patient was extubated and shifted to intensive care unit (ICU). Patient's GCS was 15. Vision in both eyes was checked and found to be normal. Hypervolemia was maintained for 5 days with intake of $3.5 \mathrm{l}$ per day. Blood pressure was maintained between 140 and $150 \mathrm{~mm}$ systolic. CT scan and 3D CT angio was done on the fifth postoperative day to ensure complete aneurysm obliteration (Figs. 4 and 5). Perimetry was done to confirm absence of visual field defects.

Patient was discharged on tenth postoperative day without any residual neurodeficits.

\section{Discussion}

Paraclinoid aneurysms are defined as aneurysms originating from the clinoidal and ophthalmic segments of the ICA [1] and constitute between $5-14 \%$ of all intracranial aneurysms [4].

Clinoidal segment is the part of the ICA between the proximal and distal dural ring. It is the "interdural" segment of the ICA.

The aneurysms arising from this segment are classified into two types:

- Anterolateral variant

- Medial variant 


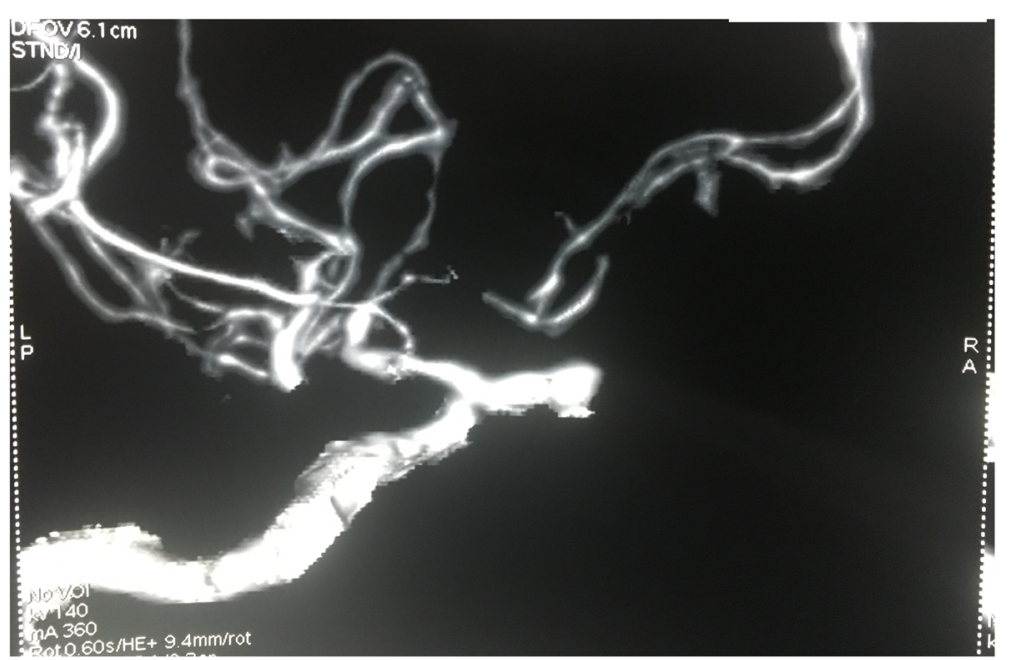

Fig. $3 \mathrm{CT}$ angiography lateral view showing the origin of the aneurysm from the ICA

The ophthalmic segment extends from the distal dural ring up to the origin of posterior communicating (PCom) artery. The ophthalmic and superior hypophyseal arteries (SHA) are the two major branches of the ophthalmic segment of the ICA.

The aneurysms arising from the ophthalmic segment are classified into three types:

- Ophthalmic artery aneurysm: arises in close relation to the ophthalmic artery and projects superiorly.

- Superior hypophyseal artery aneurysm: arises in relation to the superior hypophyseal artery and projects medially. They are further sub classified into parasellar and suprasellar variant.

- Dorsal variant: arises from the dorsal aspect of the ICA slightly distal to ophthalmic artery [1].
As can be determined by studying the angiogram, the aneurysm in this case was the suprasellar variant of the superior hypophyseal artery aneurysm.

In addition to their characteristic features of SAH, the SHA aneurysms have a propensity to grow medially and to attain a large size causing compression of the optic pathway leading to visual field defects and their detection prior to rupture. Lower limb weakness and gyrus rectus hematomas in association with an aneurysmal $\mathrm{SAH}$ is most commonly seen with ruptured A Com aneurysms, and not SHA aneurysms. In this case, the aneurysm was long and was passing below the left optic nerve to emerge in the inter-optic space, leading to this unusual clinical presentation.

Endovascular treatment was not preferred in this case because of following reasons:

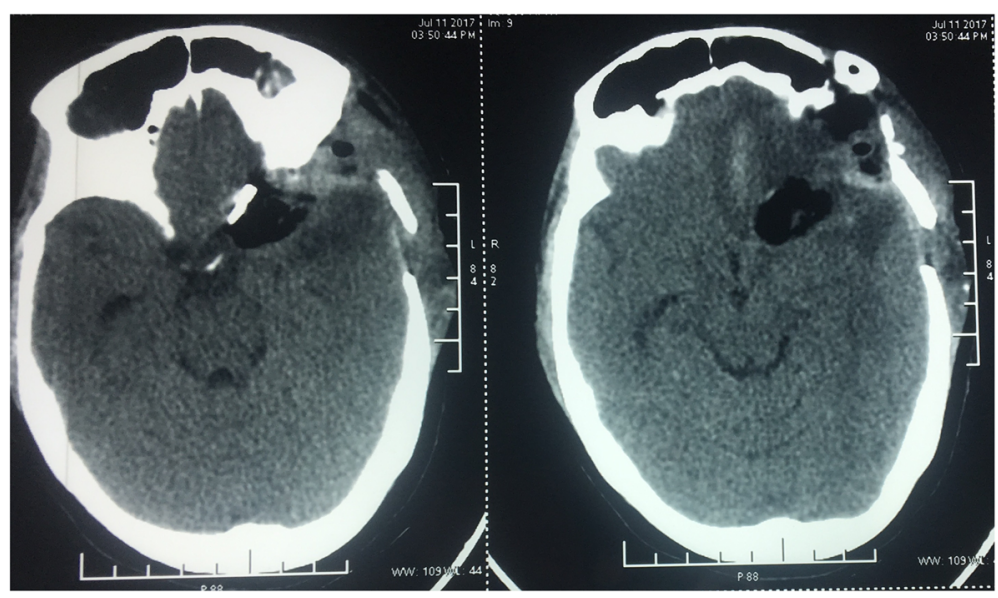

Fig. 4 Showing the drilled clinoid and optic roof on the left side 


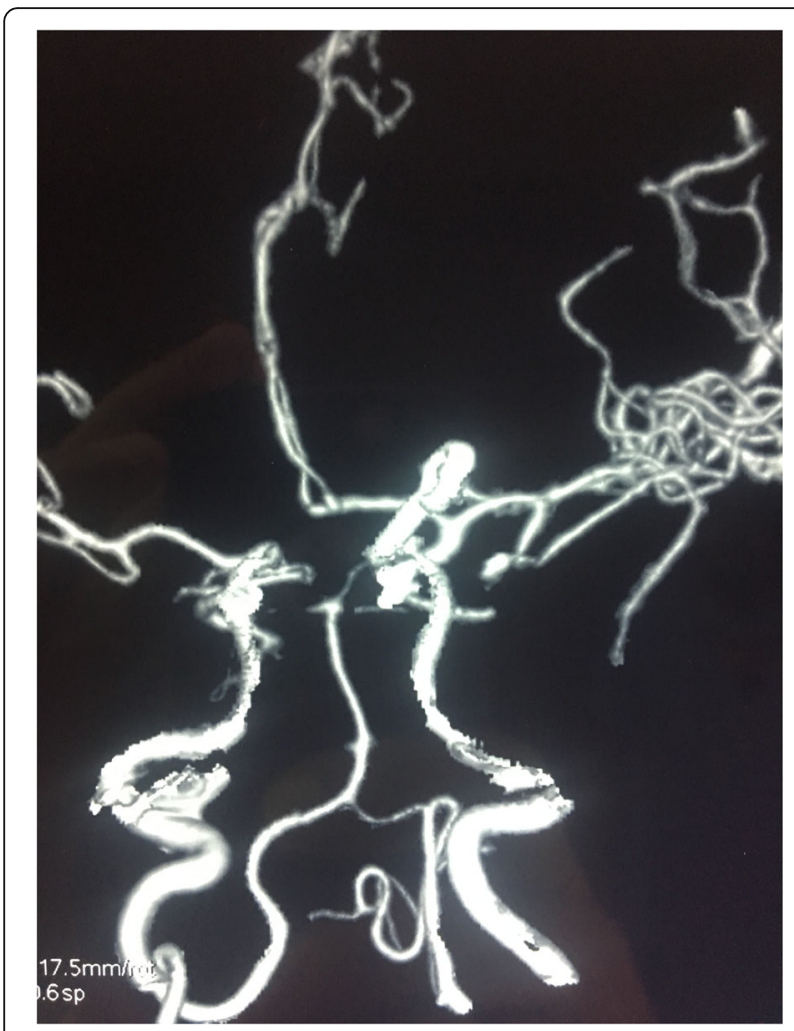

Fig. 5 Post-operative $C T$ angio graphs showing the clip in situ with patent ICA and its branches

1. Endovascular treatment does not relieve mass effect and even may lead to a larger size of aneurysm leading to pressure on the optic nerve with consequent visual field defects [5].

2. The tortuosity of the ICA in this region makes coiling difficult.

3. Coiling in this type of aneurysms is associated with a high rate of recurrence [6].

4. Endovascular treatment is not available at present in the government hospital where the patient was treated, and also in many hospitals across the country. The endovascular treatment is very expensive in the private hospitals in our country and majority of the patients cannot afford the treatment cost. Hence, clipping still remains the most economical and cost effective modality to treat most ruptured aneurysms including paraclinoid aneurysms with no significant difference in outcome as compared to the very expensive coiling techniques [7].

However, newer endovascular techniques using flow diverters and pipeline embolisation device have shown promising results in terms of improvement of visual symptoms, obliteration rate, complications and recurrence and may play a greater role in future in treatment of paraclinoid aneurysms [8]. However, financial constraints and availability of infrastructure for coiling will continue to be a major hurdle for these endovascular techniques particularly in developing countries around the world.

Surgery, though effective, presents unique challenges.

Gaining proximal control requires exposing the carotid artery in the neck.

Adequate visualisation of the neck requires intricate drilling of the anterior clinoid and the optic roof (Fig. 5). The distal dural ring needs to be opened to adequately mobilise the carotid.

In this case, the dome was adherent to the undersurface of the frontal lobe. Hence, the frontal lobe was fully dissected off the chasm and the right optic nerve only after the aneurysm was secured at the neck.

Delaying the surgery till 10th day following the ictus resulted in resolution of the mono paresis and resulted in a more relaxed brain which helped in drilling of the clinoid. Majority of studies do not show any difference in the incidence of vasospasm and outcome in good grade patients when aneurysms are clipped in the interval of 4 to 10 days of ictus. However, our experience has shown that clipping the aneurysm in this interval leads to a higher incidence of post-op vasospasm and poor outcome [3]. Hence, we clip aneurysm in the first 3 days or after 10 days of the ictus.

\section{Concluding remarks}

This case brings to light an unusual presentation of an intracranial ruptured aneurysm. Also, though endovascular treatment is fast coming up as the favoured modality in treating aneurysms, microsurgical clipping will continue to play major role in the treatment of aneurysms particularly in the developing countries where the cost of treatment renders endovascular modality quite unaffordable for many.

\section{Acknowledgements}

Nil

\section{Authors' contributions}

Both the authors were involved in the treatment of the patient. The manuscript was prepared by both the authors working together. Preparation of the manuscript, figures and references was all done together by both the authors. The operation was carried out by the corresponding (senior) author and the second author assisted during the operation. Both authors read and approved the final manuscript.

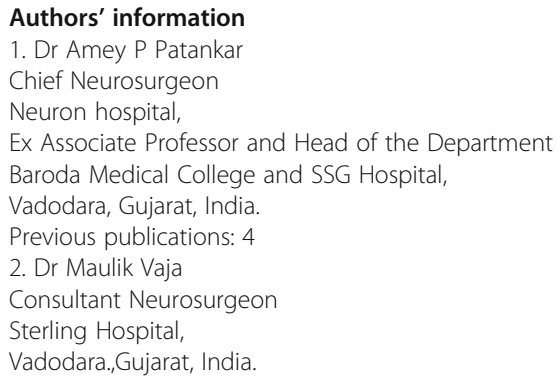


Funding

We have not received any funding from any institution or person for this case report.

\section{Availability of data and materials}

All data generated and analysed in this study is included in the published article and the figures.

\section{Ethics approval and consent to participate}

Not applicable

\section{Consent for publication}

We have uploaded consent of patient in supplementary material section. We the authors confirm that an informed written consent for publication of this case report has been obtained from the patient. The duly signed form has been uploaded in the supplementary material section.

\section{Competing interests}

The authors declare that they have no competing interests.

To carry out the operation standard neurosurgical instruments and equipments were used. For the study no additional equipment or instruments were used. The equipment used to perform the operations were: Neurosurgical operating microscope(Company BHEL, manufactured 1990, India). Stryker drill and craniotome (Company Stryker, brand CORE,manufactured 2012, USA).

Titanium Yasargil aneurysm clip by Aesculap Germany.

Sugita head clamp manufactured by Mahalsaha Technology, 2013, India Electrocautery machine (L\&T, Maestero, 2011, India).

Other standard neurosurgical insurgents and equipments like bipolar forceps, sutures etc were used.

\section{Author details}

'Department of Neurosurgery, Baroda Medical College and SSG Hospital, 703, Rajarshi Darshan Tower, Near Jalaram Mandir, Karelibag, Vadodara, Gujarat 390018, India. ${ }^{2}$ Sterling Hospital, Vadodara, Gujarat, India.

Received: 26 July 2018 Accepted: 6 September 2019 Published online: 18 September 2019

\section{References}

1. Du R, Day A. Microsurgery of paraclinoid aneurysms. In: Youmans JR, editor. Neurological Surgery, vol. 4. 6th ed. Philadelphia: WB Saunders; 2011. p. 3824-33.

2. Kassell NF, Torner JC, Jane JA, Haley EC Jr, Adams HP. The international cooperative study on the timing of aneurysm surgery part 2: Surgical results. J Neurosurg. 1990;73:37-47.

3. Lawton MT. Ophthalmic artery aneurysms. In: Lawton MT, editor. Seven Aneurysms - Tenets and techniques for Clipping. ed 2 ed. New York: Thieme; 2012. p. 121-46.

4. Godbole C, Behari S, Bhaisora K, Sardhara J, Srivastava A, Mehrotra A, et al. Surgery for superior hypophyseal artery aneurysms: a new classification and surgical considerations. Neurol India. 2017;65:588-99.

5. Schmidt GW, Oster SF, Golnik KC, Tumialán LM, Biousse V, Turbin R, et al. Isolated progressive visual loss after coiling of paraclinoid aneurysms. Am 」 Neuroradiol. 2007:28(10):1882-9.

6. Loumiotis I, D'Urso PI, Tawk R, Cloft HJ, Kallmes DF, Kairouz V, et al. Endovascular treatment of ruptured paraclinoid aneurysms: results, complications and follow-up. Am J Neuroradiol. 2012;33(4):632-7.

7. Bae DH, Kim JM, Won YD, Choi KS, Cheong JH, Yi HJ, et al. Clinical outcome of paraclinoid internal carotid artery aneurysms after microsurgical neck clipping in comparison with endovascular embolisation. J Cerebrovasc Endovasc Neurosurg. 2014;16(3):225-34

8. Silva MA, See AP, Khandelwal P, Mahapatra A, Frerichs KU, Du R, et al. Comparison of flow diversion with clipping and coiling for the treatment of paraclinoid aneurysm in 115 patients. J Neurosurg. 2018:1-8.

\section{Publisher's Note}

Springer Nature remains neutral with regard to jurisdictional claims in published maps and institutional affiliations.

\section{Submit your manuscript to a SpringerOpen ${ }^{\circ}$ journal and benefit from:}

- Convenient online submission

- Rigorous peer review

- Open access: articles freely available online

- High visibility within the field

- Retaining the copyright to your article

Submit your next manuscript at $\boldsymbol{\nabla}$ springeropen.com 